\title{
北喜马拉雅错那洞穹窿深部三维电性结构 及其构造意义
}

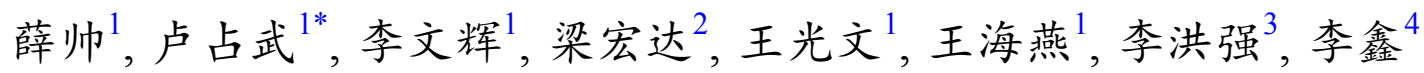

1. 中国地质科学院地质研究所, 自然资源部深地动力学重点实验室, 北京 100037 ;

2. 中国地质科学院地球物理地球化学勘查研究所, 廊坊 065000 ;

3. 中国地质科学院, 北京 100037 ;

4. 中国科学院地质与地球物理研究所, 岩石圈演化国家重点实验室, 北京 100029

* 通讯作者, E-mail: luzhanwu78@163.com

收稿日期: 2021-07-04; 收修改稿日期: 2021-12-19; 接受日期: 2022-02-07; 网络版发表日期: 2022-06-14

国家自然科学基金项目(批准号: 91962109、42174094)、第二次青藏高原综合科学考察研究项目(编号: 2019QZKK0701)、中国地质调查局地 质调查项目(编号: DD20190016)和中国地质科学院基本科研业务费项目(编号: J2015)资助

摘要北喜马拉雅片麻岩穹窿作为青藏高原南部广泛分布的伸展构造之一, 是研究后碰撞地壳变形和岩浆活动 以及多金属成矿作用的重要窗口。然而, 北喜马拉雅穹窑构造的深部成因机制仍存在争议. 文章利用大地电磁法 对北喜马拉雅错那洞穹窒构造开展深部探测研究, 分析穹窒区域大地电磁测深曲线特征和相位张量, 并通过三维

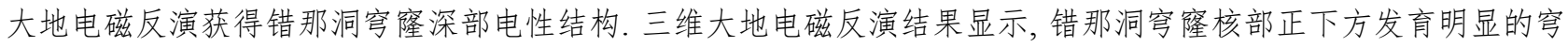
形低阻异常，上覆高阻体，且环穹察分布显著的低阻异常带. 地壳 1 20 km深度范围积分的纵向电导显示，错那洞 穹穉核部的纵向电导平均约 $10000 \mathrm{~S}$, 分析认为穹窟核部的高导异常可类比于火山岩浆, 主要为地壳部分熔融的结

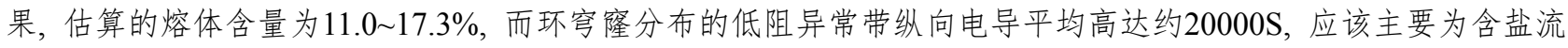
体所致. 结合已有的地质-地球化学资料, 支持错那洞穹窟经历了岩浆底辟作用。研究认为, 在藏南东西向伸展作 用背景下, 深部地壳部分熔融不断聚集于穹窑下方, 从而岩浆底辟形成了错那洞穹窡构造。同时, 大地电磁结果支 持错那洞穹㶻构造为(稀有)多金属成矿作用提供了丰富的成矿流体和含矿流体运移空间.

关键词错那洞穹㶻, 大地电磁, 北喜马拉雅穹㶻, 岩浆底辟, 部分熔融, 伸展作用

\section{1 前言}

新生代印度与欧亚大陆碰撞造山作用，导致了南 喜马拉雅的逆冲推覆体系和喜马拉雅山脉的隆升，但 碰撞带上下盘(拉萨地块和北喜马拉雅)则经历了显著
的伸展作用和强烈的岩浆活动, 形成了多种形式的伸 展构造和大规模岩浆岩发育，并伴随多金属成矿作用 (Burg等, 1984; Burchfiel和Royden, 1985; Armijo等, 1986; Tapponnier等, 2001; Yin, 2006; 许志琴等, 2006; 侯增谦等, 2006; 张进江, 2007; Zeng等, 2011; Zhang等,

\footnotetext{
中文引用格式: 薛帅, 卢占武, 李文辉, 梁宏达, 王光文, 王海燕, 李洪强, 李金金. 2022. 北喜马拉雅错那洞穹窿深部三维电性结构及其构造意义. 中国科学: 地球 科学, 52(8): 1516-1531, doi: 10.1360/SSTe-2021-0193

英文引用格式: Xue S, Lu Z, Li W, Liang H, Wang G, Wang H, Li H, Li X. 2022. Three-dimensional electrical resistivity structure beneath the Cuonadong dome in the Northern Himalayas revealed by magnetotelluric data and its implication. Science China Earth Sciences, 65(8): 1538-1553, https://doi.org/ $10.1007 / \mathrm{s} 11430-021-9900-\mathrm{y}$
} 
2012; Hou等, 2012; 吴福元等, 2015). 青藏高原南部的 伸展构造主要形成于后碰撞伸展与成矿阶段(约 25 0Ma)(侯增谦等, 2006; 张进江, 2007; Hou等, 2012; Zhang等, 2012), 是青藏高原发育最广泛、特征最明显 的构造样式之一，主要包括近东西走向的藏南拆离系 (STDS)、近南北走向的藏南裂谷系(NSTR)和大量的北 喜马拉雅片麻岩穹窡构造(如NHGD). 其中片麻岩穹窡 构造主要发育于特提斯喜马拉雅构造带内, 保存了陆 陆碰撞过程中挤压和伸展活动、高级变质、地壳深熔 岩浆作用和浅表响应的重要信息, 是研究造山带深部 地壳构造变形和岩浆活动等大陆动力学过程以及多金 属成矿作用的重要窗口(Burg等, 1984; Le Fort等, 1987; Harrison等, 1997; Lee等, 2000, 2006; 李德威等, 2003; 许 志琴等, 2006; 张进江, 2007; 曾令森等, 2009; 吴福元等, 2015; 李光明等, 2017; 王汝成等, 2017; Wu等, 2020).

位于雅鲁藏布江缝合带(YZS)以南的北喜马拉雅 (图1a)，发育了一系列东西向断续分布的串珠状穹窡， 并伴随出露淡色花岗岩, 形成了北喜马拉雅片麻岩穹 窡带(NHGD)和特提斯喜马拉雅淡色花岗岩带，同时 在STDS上下部位分布了另一条高喜马拉雅淡色花岗 岩带(Zeng等, 2011; 吴福元等, 2015; Wu等, 2020), 并 发现了错那洞穹窟(李光明等, 2017; Fu等, 2017, 2018; 张林奎等, 2018; 焦彦杰等, 2019). 目前, 国内外学者针 对北喜马拉雅穹㶻构造和淡色花岗岩开展了大量的 研究(Burg等, 1984; Le Fort等, 1987; Harrison等, 1997; Lee等, 2000, 2006; 吴福元等, 2015; 王汝成等, 2017), 如雅拉香波穹窿(张波等, 2005; 曾令森等, 2009; Zeng 等, 2011; 董否等, 2020)、康马穹緷(Lee等, 2000)、拉 轨岗日穹㝫(李德威等, 2003; 许志琴等, 2006)、麻布 迦穹窿(Lee等, 2006; Li等, 2021)、错那洞穹㶻(李光明 等, 2017; Fu等, 2017, 2018; 高利娥等, 2017; 张林奎等, 2018; 焦彦杰等, 2019)等, 提出了多种片麻岩穹窒的成 因模式. Burg等(1984)首先提出在印度大陆低角度俯 冲过程中发育了逆冲断坡构造或叠置构造, 导致高级 变质岩石的抬升和出露，形成了穹隆构造，该模式获 得了多位学者和深反射地震探测的支持(Lee等, 2000, 2006; Yin, 2006; Gao等, 2016; Dong X等, 2020). 而李 德威等(2003)通过研究拉轨岗日多个穹窒, 认为这些 穹㶻是一系列具有伸展构造性质的变质核杂岩, 并与 STDS之间存在十分密切的时空关系和成因联系(许志 琴等, 2006; 张进江, 2007; Zhang等, 2012). Le Fort等
(1987)提出了岩浆底辟模式来解释北喜马拉雅穹窡构 造和淡色花岗岩的形成, 认为在主中央逆冲断层 (MCT)之上发生了富水深熔作用, 因浮力上升的岩浆 底辟形成了寄隆构造和淡色花岗岩. Harrison等(1997) 则根据数值模拟结果, 研究认为喜马拉雅连续滑脱层 或低角度逆冲断裂的剪切生热可引起高喜马拉雅和 特提斯喜马拉雅的地壳深熔作用, 支持岩浆底辟模式. 同样利用数值模拟方法, Beaumont等(2001, 2004)研究 认为青藏高原腹地增厚地壳发生了中下地壳部分熔 融和有效黏度的降低 $\left(\leq 10{ }^{19} \mathrm{~Pa} \mathrm{~s}\right)$, 随着印度大陆的持 续向北俯冲和重力作用下，弱中下地壳向四周横向流 动, 结合地表的集中剥蚀作用, 南向的管道流(或地壳 流)导致了北喜马拉雅STDS和穹窡等构造以及花岗岩 出露，这种青藏高原广泛发育的弱中下地壳及其向外 的大规模流动被大量的动力学模拟和地球物理数据 所支持(Clark和Royden，2000; Unsworth等，2004， 2005; Bai等，2010; Zhao等，2012; 王绪本等，2018; Pang等, 2018; Yu等, 2020; Sun等, 2020; Xue等, 2021). 同时, 越来越多的研究认为北喜马拉雅穹窡构造可能 无法完全用单一模式来解释，而是多种模式共同作用 的结果, 存在比较复杂的构造-岩浆活动和不同的变形 过程(Lee等, 2000, 2006; 张进江, 2007; Guo等, 2008; Zhang等, 2012).

前期关于藏南穹窟构造的研究大都基于地质-地 球化学资料和数值模拟结果, 而针对穹窡构造的深部 地球物理探测研究则相对较少, 缺乏穹窡构造的深部 结构特征和流变学状态等信息, 从而制约了对北喜马 拉雅穹窡构造的研究. 大地电磁法对深部流体(含盐流 体、部分熔融等)比较敏感, 在克拉通和造山带深部结 构以及青藏高原及其周缘弱中下地壳的探测研究中被 广泛应用(Unsworth等, 2004, 2005; Bai等, 2010; 金胜 等, 2010; Dong H等, 2016, 2020; 王绪本等, 2018; Ye等, 2018; 徐义贤等, 2019; 陈小斌等, 2019; Xue等, 2019, 2021; 胡祥云等, 2020; Gao等, 2020; Yu等, 2020). 因此, 本文使用大地电磁方法对北喜马拉雅错那洞穹窟构造 开展深部探测研究, 获得错那洞穹窡的深部三维电性 结构，通过分析错那洞穹窡区域的深部电性结构特征 和流变学状态, 研究探讨北喜马拉雅穹䏺构造的深部 成因机制和错那洞穹窒区域的多金属成矿作用。错那 洞穹窒作为新发现的北喜马拉雅穹窒构造, 目前在该 区域发现了铍等稀有金属和铅锌、金锑等多金属成矿 

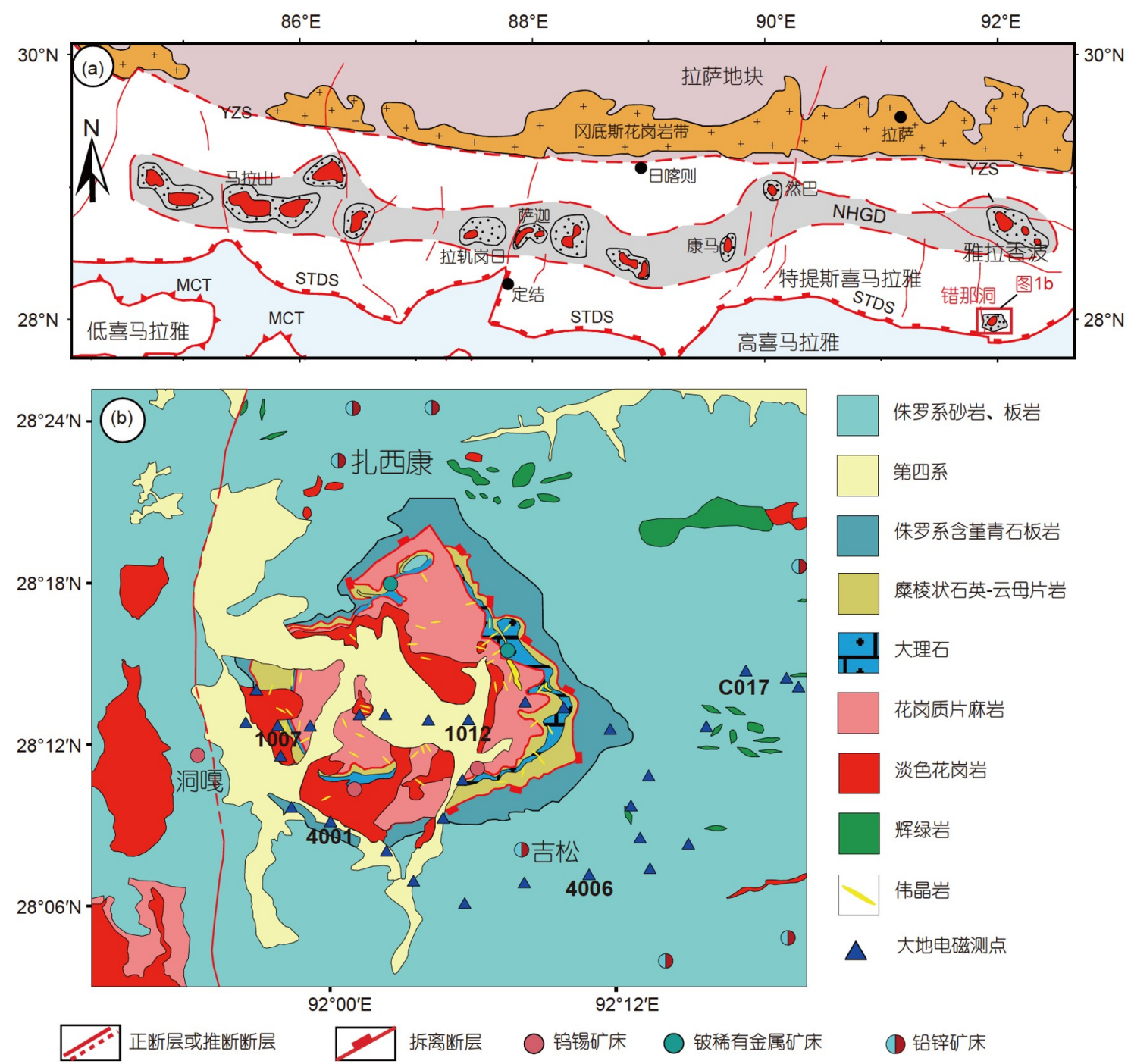

图 1 藏南喜马拉雅造山带(a)和错那洞穹窒(b)地质简图

(a) 修改自Zeng等(2011); (b) 修改自李光明等(2017)和Fu等(2018)

作用，具有巨大的成矿潜力(李光明等，2017； Fu等， 2017; 张林奎等, 2018; 夏祥标等, 2019; 梁维, 2019; 梁维等, 2020).

\section{2 区域地质背景}

北喜马拉雅碰撞构造带主要位于雅鲁藏布江缝合 带(YZS)和主中央逆冲断裂(MCT)之间(图1a)，构造带 内发育有藏南拆离系(STDS)、南北向裂谷系(NSTR) 和片麻岩穹㶻三种伸展构造(许志琴等，2006; 侯增谦 等, 2006; 张进江, 2007; 吴福元等, 2015), 其中STDS 是
世界上规模最大的正断层体系，将低级变质的特提斯 喜马拉雅沉积岩系直接叠置于高级变质的高喜马拉雅 结晶岩系之上(Burchfiel和Royden, 1985; 张进江, 2007; 王晓先等，2016), 南北向裂谷系主要由7个裂谷组成, 自西向东比较规律的分布, 南端切割STDS, 北部延伸 至拉萨地块或更北(Armijo等，1986; 张进江，2007; Zhang等, 2012; Xue等, 2021), 片麻岩穹䏺构造则主要 分布在北喜马拉雅穹㶻带(NHGD)和靠近STDS位置. 错那洞穹窿(图1b)位于特提斯喜马拉雅东南端，靠近 STDS和南北向错那-沃卡裂谷, 紧邻拿日雍错, 距离雅 拉香波穹窿正南约 $40 \mathrm{~km}$ (李光明等, 2017). 
错那洞穹窒具有典型的北喜马拉雅穹窡构造特 征, 表现为三层结构型式, 分为核、幔和边3部分, 核部 与幔部之间的下拆离断层为一韧性低角度正断层，是 变形最为强烈的地质界线, 上拆离断层则为幔部和边 部之间发育的脆性低角度正断层，两者主要见于错那 洞穹窡的北侧、东侧以及东南侧(图1b)(李光明等, 2017；Fu等，2017，2018；张林奎等，2018; 夏祥标等, 2019). 核部主要由糜棱状花岗片麻岩和后期多期次侵 入的中新世淡色花岗岩组成(林涁等，2016; 张志等, 2017; 高利娥等, 2017). 幔部岩石组合主要为眼球状 古生代正片麻岩、副片麻岩和强烈变形的石英二云母 片岩夹糜棱岩化碳酸盐岩, 从外向内岩石变质程度逐 渐加深, 构造变形依次强烈, 发育多期线理构造, 靠近 下拆离断层处侵入大量顺层的淡色花岗质岩脉(李光 明等, 2017; 张志等, 2017; Fu等, 2017, 2018; 张林奎等, 2018). 边部主要为浅变质或未变质的侏罗纪的特提斯 沉积岩系日当组, 岩石组合主要为砂岩、粉砂岩、泥 页岩、砂质板岩、钙质板岩、千枚岩等，变质程度从 内而外逐渐变弱. 根据穹窒内发育的线理构造及其运 动学特征, 错那洞穹窟主要经历了 4 期构造变形, 分别 对应于初期向南逆冲、早期近N-S 向伸展、主期近E$\mathrm{W}$ 向伸展和晚期滑塌构造运动(Fu等, 2017, 2018; 张志 等, 2017; 张林奎等, 2018).

目前, 以错那洞穹隆为核心, 从内往外发育了稀有 金属 $\rightarrow \mathrm{W}+\mathrm{Sn}+\mathrm{Be} \rightarrow \mathrm{Pb}+\mathrm{Zn}+\mathrm{Au}+\mathrm{Sb} \rightarrow \mathrm{Au}+\mathrm{Sb}$ 从高温至 低温的分带成矿作用(图1b)，在穹窡核部大面积分布 的伟晶岩脉中发现了铍 $(\mathrm{Be}) 、$ 、铭 $(\mathrm{Rb})$ 、锂 $(\mathrm{Li})$ 等稀有 金属矿化; 往外在穹窡幔部大理岩与花岗岩或花岗伟 晶岩接触带发生了强烈的接触交代变质作用, 形成了 连续稳定、赋存铍铇锡稀有多金属矿体的矽卡岩带; 而在穹壂外围，靠近内侧发现了大量的铅锌多金属矿 床; 在穹窡最外侧, 则发育金锑或锑矿床, 形成了受错 那洞宫窟淡色花岗岩岩浆-热液控制的大型多金属矿 集区(聂凤军等，2005; 杨竹森等，2006；侯增谦等， 2006; 李光明等, 2017; 张林奎等, 2018; 夏祥标等, 2019; 梁维等, 2020).

\section{3 大地电磁数据采集、处理分析与反演}

\section{1 数据采集与处理}

本文大地电磁数据主要由一条横跨错那洞穹窒的
东西向测线和分布于穹窿区域中南部的测点组成，共 30 个测点(图1b). 东西向测线西起错那-沃卡裂谷, 横 穿穹窡核部、幔部和边部以及拆离断层等构造单元, 东至错那县觉拉乡附近, 沿测线测点共 16 个, 测线长约 $36 \mathrm{~km}$, 平均点距约 $3 \mathrm{~km}$, 其他测点主要分布于错那-沃 卡裂谷和穹㶻边部, 大致环穹窡展布, 平均点距约 $3 \mathrm{~km}$. 野外大地电磁数据采集于 2020 和 2021 年, 每个测点的 观测时间不小于 $20 \mathrm{~h}$, 使用加拿大凤凰公司生产的V52000大地电磁仪器(http://www.phoenix-geophysics. com).

本文采用SSMT2000和MT-Editor软件对大地电磁 数据进行时频转换、Robust估算(Egbert，1997)和功率 谱挑选等处理, 获得了大地电磁全阻抗张量数据 $\left(Z_{x x}\right.$ 、 $Z_{x y} 、 Z_{y x} 、 Z_{y y}$ ). 图2为部分典型测点的大地电磁视电阻 率和相位测深曲线, 可以看出, 大地电磁测深曲线比较 光滑, 具有较高的质量, 形态总体为 $\mathrm{K}$ 型和 KHK型曲 线, 主要表现为两个显著的特征: (1) 大部分测点视电 阻率测深曲线在约 $10 \mathrm{~Hz}$ 附近开始明显下降(如测点 1012、4006和 C017), 视电阻率从高频段(约 100 10Hz) 的约 $100 \sim 1000 \Omega \cdot \mathrm{m}$ 降至低频段 (约 100 1000s) 的 $\leq 1 \Omega \cdot \mathrm{m}$, 预示研究区域深部存在显著的低阻异常; (2) 多个测点相位存在超象限现象, 同时视电阻率曲线呈 现较明显波动起伏，这些测点多分布于穹窿幔部和边 部(如测点1007), 相位超象限现象很难用二维同性介 质模拟和解释，一般需要引入较复杂的三维介质或各 向异性介质，如在高阻介质中镶嵌高电导率的三维高 导体或环形高导体(Heise和Pous, 2003; Xiao等, 2013). 由于研究区域地势险峻、道路崎岖且高原环境恶劣, 大部分测点沿裂谷和山谷布设, 而这些区域也是城 镇、道路和高压线等相对密集地区, 导致部分测点受 到了较严重的噪声干扰, 在后续数据处理中剔除了受 影响的频点数据, 并对部分重点区域测点进行了补测.

\section{2 相位张量分析}

大地电磁相位张量分析方法自Caldwell等(2004) 提出后, 由于其不需要事先对地下电性结构维性作出 任何前提假设等优点, 被广泛地应用于地下维性和深 部电导率变化等分析中(Hill等，2009; Xiao等，2013; Meqbel等, 2014, 2016; Zhang等, 2016; Dong H等, 2016, 2020; Gao等, 2020; Xue等, 2019, 2021). 大地电 磁相位张量常以一系列椭圆来表示, 椭圆的长轴或短 

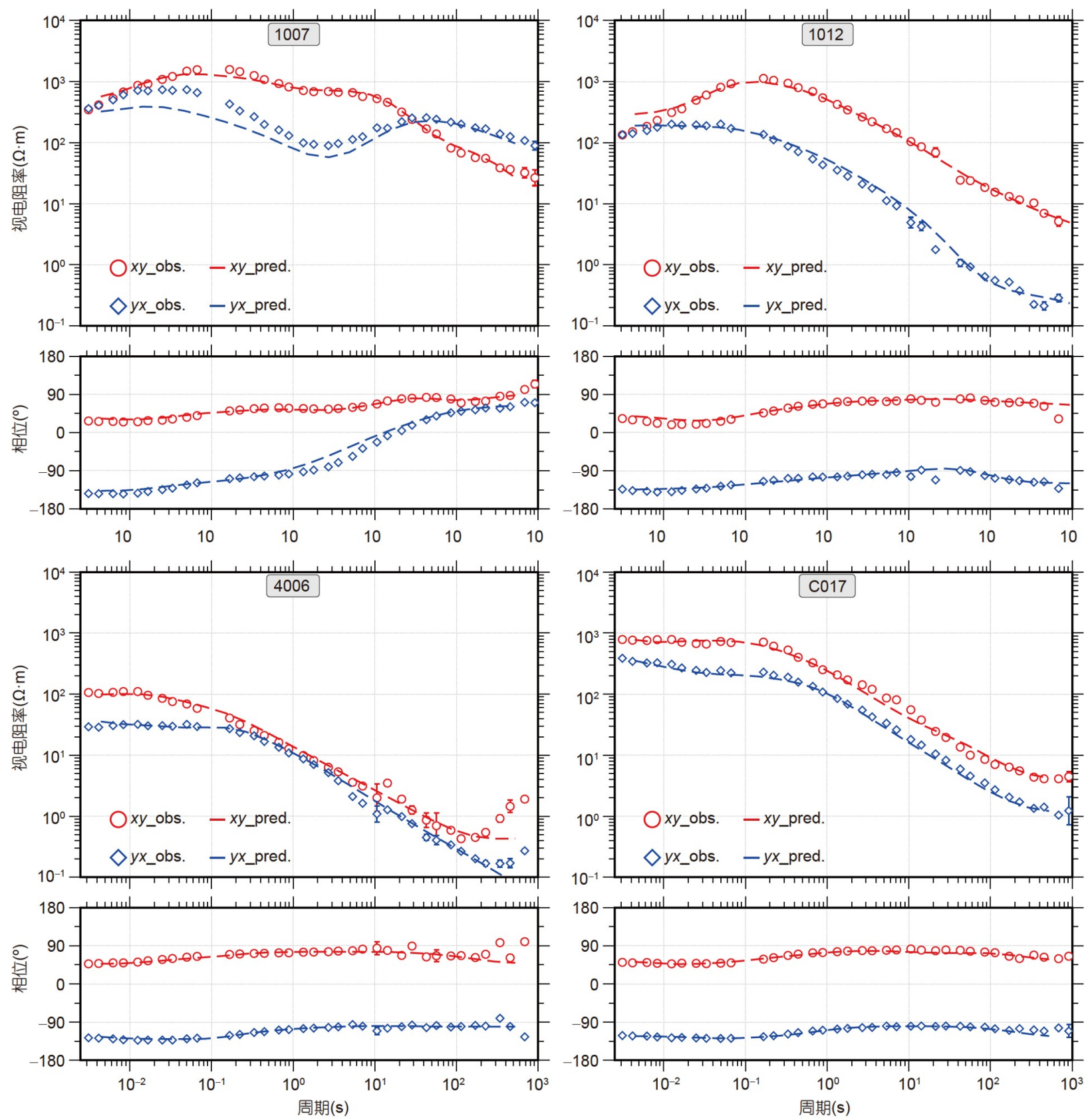

图 2 错那洞穹窟区域典型大地电磁测深曲线

测点1007、1012、4006和C017位置见图1b. 红色空心圆和蓝色空心菱形分别为观测的 $x y$ 和 $y x$ 模式, 红色和蓝色线则为相应的反演模拟结果

轴可指示地下电性结构的横向变化, 椭圆的填充色代 表相位张量偏离度 $|\beta|$, 当 $|\beta|$ 值较大时(如 $|\beta|>3^{\circ}$ ), 说明深 部结构表现为三维性(Bibby等, 2005; Booker, 2014). 图 3 展示了错那洞穹㶻研究区域不同周期的大地电磁相 位张量, 在0.01 0.1s 周期范围内(图3a), 大部分测点的 相位张量 $|\beta|$ 值较小, 说明浅部存在相对简单的电性结
构，应该反映了浅表第四纪和特提斯沉积系. 当周期 为1s时(图3b), 离穹㶻核部较远的边部, 大部分测点相 位张量 $|\beta|$ 值仍然较小, 可能反映了穹窡边部保存较好 的厚沉积层. 而当周期 $>0.1 \mathrm{~s}$ (图 $3 \mathrm{~b} \sim 3 \mathrm{~d})$, 位于穹蕯核部 和幔部的测点相位张量 $|\beta|$ 值显著增大, 结合比较杂乱 的椭圆长轴(或短轴)方向和大地电磁测深曲线特征(图 

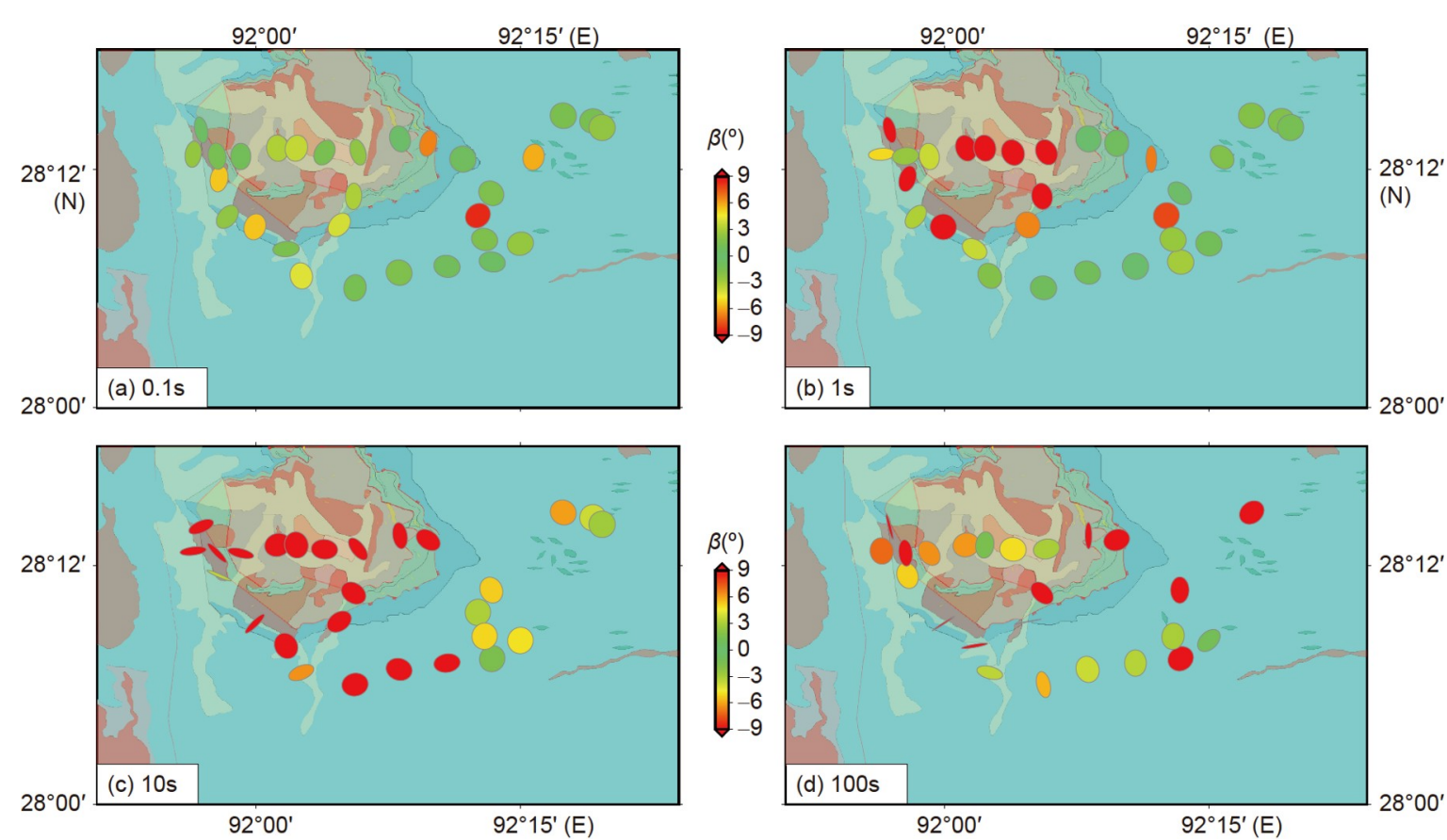

图 3 研究区域大地电磁相位张量

2)，显示错那洞穹官深部具有比较复杂的三维性电性 结构. 因此, 为了获得有效可靠的错那洞穹㶻深部电 性结构, 需要开展大地电磁三维反演模拟研究.

\section{3 大地电磁三维反演}

本文采用Egbert和Kelbert(2012)开发的基于有限 差分数值模拟和非线性共轭梯度方法的大地电磁三维 反演程序包ModEM，对错那洞穹窡区域的大地电磁数 据进行三维反演计算，该算法被大量应用于大地电磁 数据正反演模拟研究中(Meqbel等, 2014, 2016; Zhang 等, 2016; Dong H等, 2016, 2020; 殷长春等, 2020; Gao 等, 2020; Sun等, 2020; Yu等, 2020; 李世文等, 2020; Xue等, 2019, 2021). 在本文三维大地电磁反演中, 有 30 个测点参与，每个测点共约 22 个频点全阻抗张量响应 数据, 等对数间隔的分布在周期约 $0.003 \sim 1000 \mathrm{~s}$ 范围内, 反演数据误差限设为 $\left|Z_{x y} * Z_{y x}\right|^{1 / 2} \times 5 \%$. 三维反演网格模 型由长方体组成, 剖分方式上, 纵向 $(z)$ 网格首层厚度 设为 $30 \mathrm{~m}$, 往下各层厚度按照 1.2 倍数递增, 直至深度 $800 \mathrm{~km}$. 横向上 $(x, y)$, 在反演模型的中心区域，按 $1.5 \mathrm{~km} \times 1.5 \mathrm{~km}$ 网格等间距剖分, 在中心区域外, 则按照 1.5 倍的比例系数向外扩展 10 个网格, 共获得 $36(x) \times 50$ $(y) \times 51(z)$ 网格. 本文的反演初始模型为 $100 \Omega \cdot \mathrm{m}$ 均匀半
空间, 三个方向的圆滑参数均取 0.3 , 初始正则化因子 $\lambda$ 设为 100 , 并以 10 的倍数递减. 经过 205 次反演迭代, 反 演数据拟合误差从 34.8 降至 2.3 , 图 $4 \mathrm{a}$ 为反演结果各测 点拟合误差 $\mathrm{RMS}_{\text {preferred. }}$ 从拟合曲线(图2, 红色和蓝色 实线)和各测点 $\mathrm{RMS}_{\text {preferred }}$ 分布(图4a)可以看出, 三维反 演结果较好地拟合了大部分测点的大地电磁数据, 其 中, 相比于穹窡外侧大地电磁测点的较小拟合误差, 靠近穹窡核部的大地电磁测点拟合误差RMS $\mathrm{R}_{\text {preferred }}$ 相 对较大(图4a), 可能是由于穹㶻构造比较复杂的深部 三维性结构或者各向异性所致.

一般, 大地电磁法可有效约束地下低阻层或高导 层顶部, 但对于高导层的深部延伸则不敏感(Unsworth 等, 2004). 为了进一步验证大地电磁反演结果的可靠 性, 本文对反演结果进行了深度灵敏度测试, 即将三维 反演电阻率模型 $5 、 10 、 20 \mathrm{~km}$ 深度以下的电阻率替换 为 $100 \Omega \cdot \mathrm{m}$ (初始反演模型电阻率), 然后计算不同替换 深度下各测点的拟合误差 $\mathrm{RMS}_{5 \mathrm{~km} / 10 \mathrm{~km} / 20 \mathrm{~km}}$, 并求取拟 合误差差值 diff.(RMS) $=\left|\mathrm{RMS}_{\text {preferred }}-\mathrm{RMS}_{5 \mathrm{~km} / 10 \mathrm{~km} / 20 \mathrm{~km}}\right|$, 拟合误差差值diff.(RMS)的变化可反映大地电磁数据 的有效约束深度. 灵敏度测试结果显示, 当替换 5 、 10、 $20 \mathrm{~km}$ 深度以下电阻率为 $100 \Omega \cdot \mathrm{m}$ 时 (图 $4 \mathrm{~b} \sim 4 \mathrm{~d}$ ), 穹 穉中心区域的大地电磁测点拟合误差差值均明显较 

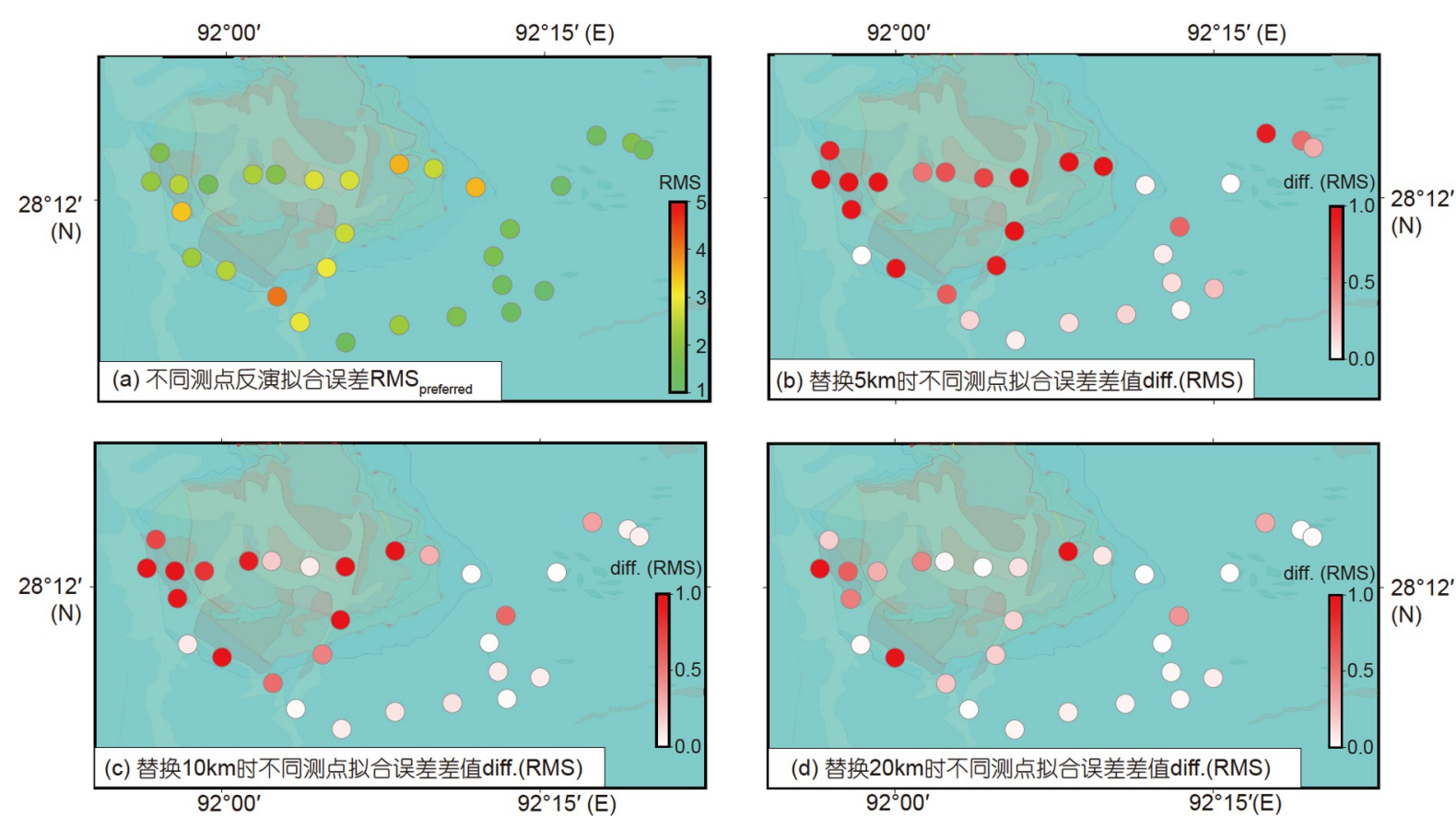

图 4 研究区域不同测点的反演拟合误差(a)及不同深度的拟合误差差值((b) (d))

(a) 不同测点的反演拟合误差 $\mathrm{RMS}_{\text {preferred }}$; (b) (d) 将 $5 、 10 、 20 \mathrm{~km}$ 深度以下置换为 $100 \Omega \cdot \mathrm{m}$ 时的拟合误差差值diff.(RMS)

大, 说明穹隆中心区域的大地电磁数据可有效约束深 度至 $220 \mathrm{~km}$. 在穹窡外侧, 当替换 5 和 $10 \mathrm{~km}$ 深度以下电 阻率时(图4b、4c), 该区域的大地电磁拟合误差差值 相对较大, 而当替换深度为 $20 \mathrm{~km}$ 时(图 $4 \mathrm{~d}$ ), 该区域的 大部分大地电磁测点拟合误差差值明显变小且多为 0 , 说明穹窟外侧区域的大地电磁数据有效约束深度约为 $10 \mathrm{~km}$.

\section{4 错那洞穹窄三维电性结构}

通过上述大地电磁数据处理、分析和三维反演计 算以及灵敏度测试等，我们获得了稳定可靠的错那洞 穹隆区域大地电磁三维反演电阻率模型. 图 5 为 4 个典 型深度(约 $3 、 8 、 14$ 和 $20 \mathrm{~km}$ )的三维反演电阻率模型水 平切片, 代表了错那洞穹窒自浅表至中地壳深度的电

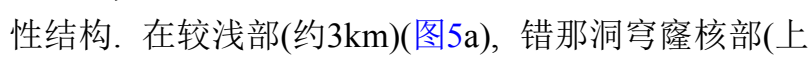
拆离断层内侧)总体表现为高阻特征, 而环穹窡则分布 三个低阻异常体 $\mathrm{C} 2 、 \mathrm{C} 3$ 和 $\mathrm{C} 4$, 其中低阻体 $\mathrm{C} 4$ 将低阻 体C2和C3连通在一起, 形成了一条近环穹㶻低阻异常 带. 当深度增加至约 $8 \mathrm{~km}$ 时(图5b), 穹碾核部正下方发 育了一个显著的低阻异常体 $\mathrm{C} 1$, 同时在穹隆东西两侧
分布低阻异常体 $\mathrm{C} 2$ 和 $\mathrm{C} 3$. 随着深度增加至约 $14 \mathrm{~km}$ (图 $5 \mathrm{c}$ )和约 $20 \mathrm{~km}$ (图 $5 \mathrm{~d}$ )时, 异常体 $\mathrm{C} 1$ 仍然存在, 并向南偏 移, 但低阻体 $\mathrm{C} 2$ 和 $\mathrm{C} 3$ 则从研究区域逐渐消失.

为了更好地展示穹窟深部结构, 本文提取了横穿 穹窟核部的深度剖面AA'和大致环穹隆剖面BB'B" (见 图5a中白色实线). 横穿穹㵚核部的剖面AA'(图6a)显 示, 在穹隆核部正下方发育显著的低阻异常体 $\mathrm{C} 1$, 自 深部约 $5 \mathrm{~km}$ 延伸至约 $20 \mathrm{~km}$ 或更深, 呈现穹形结构, 并 上覆高阻体 $\mathrm{R}$, 而且在穹䆙东西两侧分布低阻体 $\mathrm{C} 2$ 和 $\mathrm{C} 3$, 两者的底部深度约 $10 \mathrm{~km}$. 环穹隆剖面BB'B"(图6b) 与剖面 $\mathrm{AA}^{\prime}$ 电性结构特征大致相似, 但低阻体 $\mathrm{C} 1$ 的埋 深明显增大, 并且在上覆的高阻体 $R$ 中, 嵌入了显著低 阻层 $\mathrm{C} 4$, 结合三维反演结果水平切片(图5), 低阻层 $\mathrm{C} 4$ 将低阻体 $\mathrm{C} 2$ 和 $\mathrm{C} 3$ 连接在一起, 形成了环穹爯(上拆离 断层外侧)分布的低阻异常带.

\section{5 讨论}

\section{1 高导异常和流体含量估算}

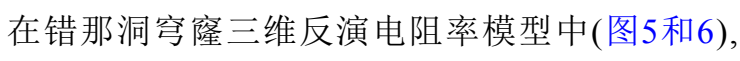
最显著的电性结构特征为穹䆙核部正下方发育的穹形 

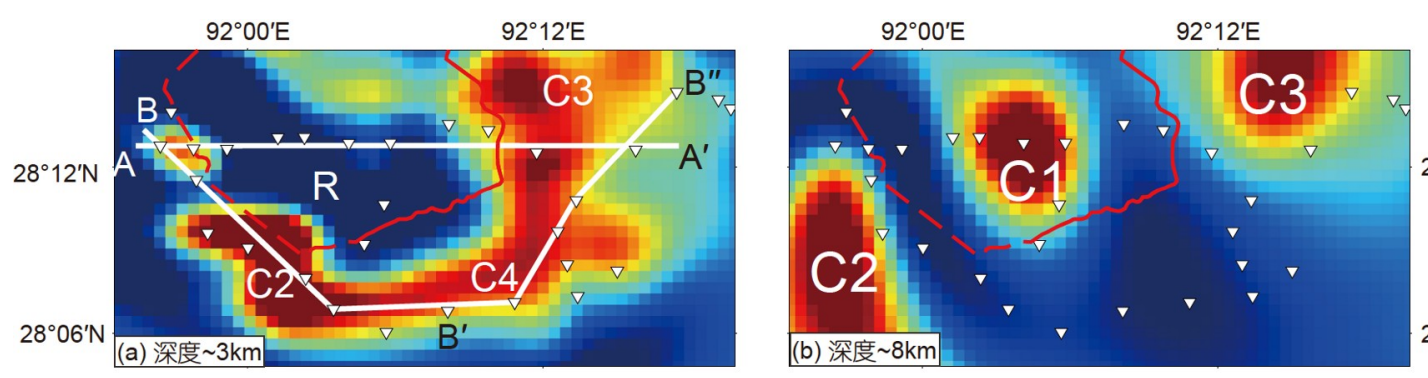

$28^{\circ} 12^{\prime} \mathrm{N}$
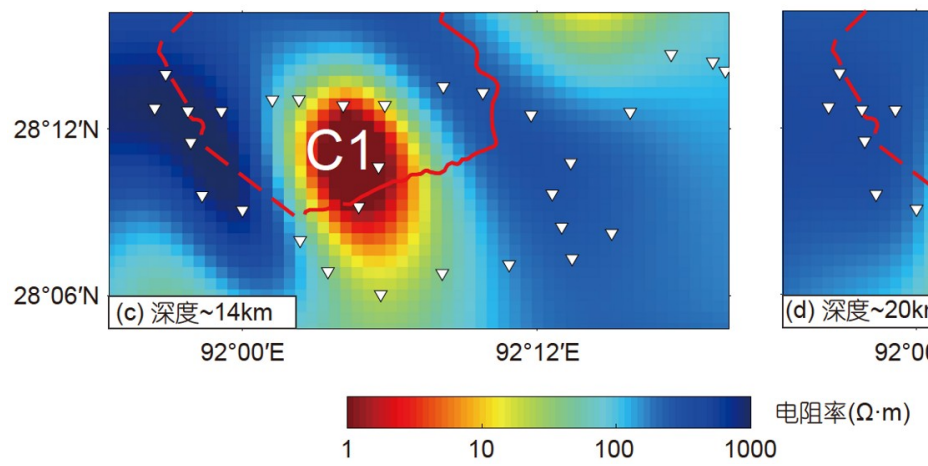

$28^{\circ} 06^{\prime} \mathrm{N}$

图 5 三维反演电阻率模型中典型深度水平切片
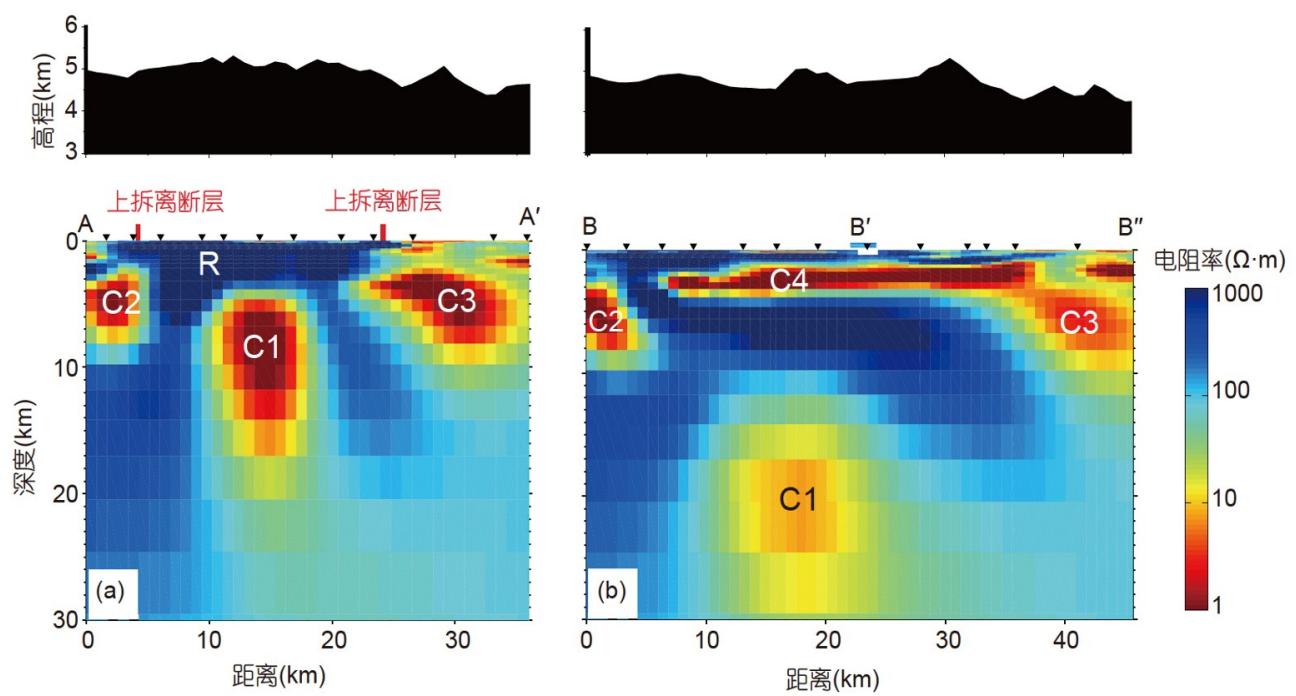

图 6 三维反演结果沿测线 $\mathrm{AA}^{\prime}$ 和 $\mathrm{BB}^{\prime} \mathrm{B}^{\prime \prime}$ 深度剖面

剖面位置见图5a

低阻异常体 $\mathrm{C} 1$ 和环穹窒(上拆离断层外侧)分布的低阻 异常带 $\mathrm{C} 2 、 \mathrm{C} 3$ 和 $\mathrm{C} 4$, 两者的最低电阻率值均 $\leq 1 \Omega \cdot \mathrm{m}$, 表现为明显的低阻高导特性. 但相较于三维反演电阻 率模型中每层的厚度和电阻率值, 大地电磁数据更有 效反映了深部电导分布(Unsworth等, 2004), 即电导率 $\sigma$ (电阻率 $\rho$ 倒数) 沿深度的积分. 为此, 本文计算了
1 20km深度范围内的纵向电导(图7). 从图7可见, 错 那洞穹窒区域纵向电导分布与三维电阻率模型特征基

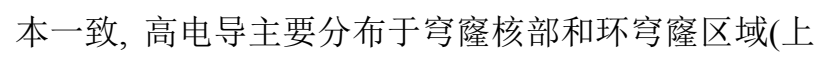
拆离断层外侧), 分别对应于三维反演结果中的低阻体 $\mathrm{C} 1 \sim \mathrm{C} 4$ (图5 和6), 穹窡核部纵向电导 $\mathrm{C} 1$ 最高可达约 $80000 \mathrm{~S}$, 平均纵向电导为约 $10000 \mathrm{~S}$, 最低电阻率为约 


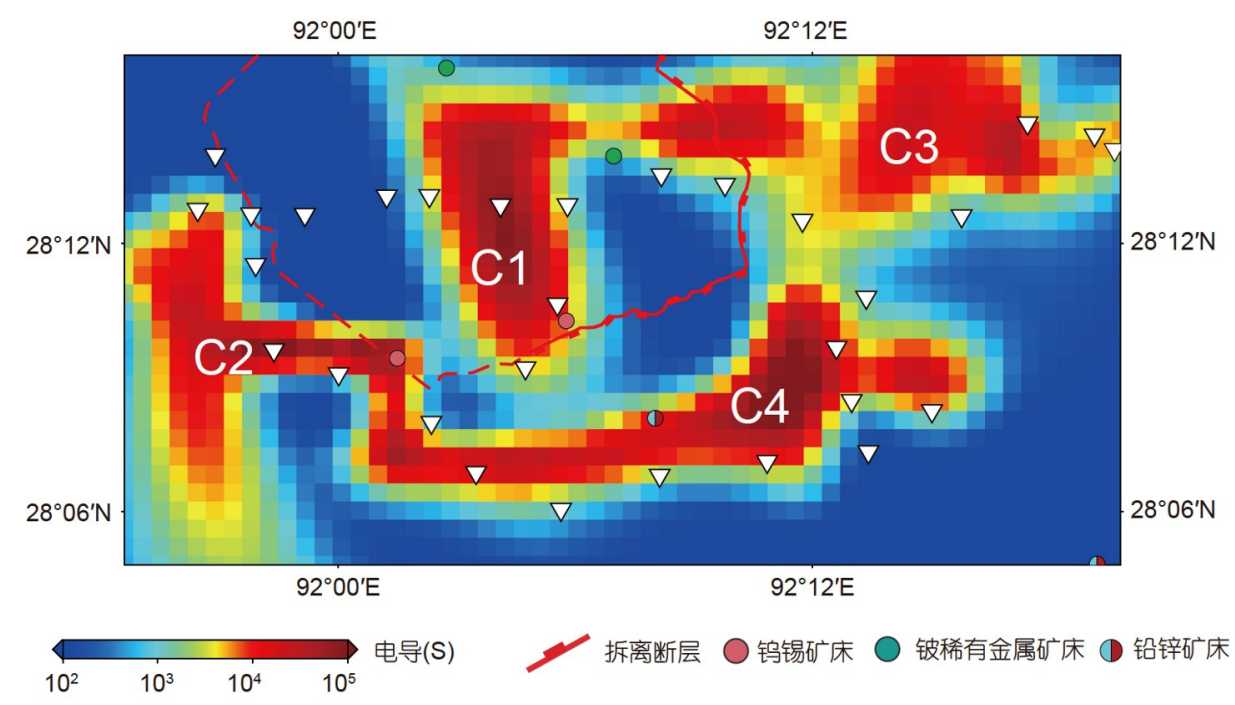

图 7 错那洞穹穉区域纵向电导分布图 1 20km深度范围电导率积分

$0.25 \Omega \cdot \mathrm{m}$, 平均电阻率约为 $2.0 \Omega \cdot \mathrm{m}$. 而环穹隆纵向电导 (C2、C3 和 C4)平均高达约 $20000 \mathrm{~S}$, 平均电阻率约为 $1.0 \Omega \cdot \mathrm{m}$, 如此低的平均电阻率与该区域观测到的低频 段(约100 1000s) 大地电磁视电阻率(图2)相一致. 同 时, 计算的电导(图7)显示错那洞穹窐核部的高导异常 $\mathrm{C} 1$ 和环穹緷高导异常带 $(\mathrm{C} 2 、 \mathrm{C} 3$ 和 $\mathrm{C} 4)$ 在穹窒的东北 部很可能相连，但由于在错那洞穹窡北部区域缺少大 地电磁测点(图1b), 限制了对该区域电性结构的有效 约束.

目前, 大量的地球物理结果显示青藏高原及其周 缘广泛分布地壳低阻低速异常(Bai等，2010；Zhao等， 2012; Bao等, 2015; Dong H等, 2016, 2020; Xie C L 等, 2017; Xue等, 2019, 2021), 其中在藏南地区开展的 大地电磁观测显示, 在喜马拉雅造山带深部18 20和 $10 \sim 13 \mathrm{~km}$ 分别存在约 0.3 和 $0.05 \sim 0.1 \mathrm{~S} \mathrm{~m}^{-1}$ 的低阻异常, 普遍研究认为这些低阻异常是地壳部分熔融结果 (Unsworth等, 2004, 2005; Hashim等, 2013; Xie C L等, 2017; Chen等, 2018). 非常巧合的是, 错那洞穹蕯核部 正下方的穹形低阻高导异常体 C1(图5和6)在形态、电 阻率值和赋存深度等方面，与新西兰Tongariro火山区 域下方发现的低阻异常非常相似, 大地电磁结果(Hill 等，2015)显示Tongariro火山区域约4 12km深度存在 一个菱形低阻异常体, 最低电阻率为 $0.2 \Omega \cdot \mathrm{m}$, 被解释 为岩浆房或地壳部分熔融, 估算的熔体含量为 $20 \sim 5 \%$, 并在野外观测完成 18 个月后，该区域发生了
两次小型火山喷发. 这种相似的低阻高导异常在美国 St Helens火山区域(Hill等，2009)、玻利维亚Uturuncu 火山(Comeau等, 2015)、日本Naruko火山(Ogawa等, 2014)和中国五大连池火山(Gao等，2020)下方均被揭 示. 因此, 结合错那洞穹窟核部出露的淡色花岗岩(李 光明等, 2017)以及穹㶻周边分布的地热田(如古堆地 热田)和浅成低温热液型矿床(聂凤军等, 2005; 侯增谦 等, 2006; 杨竹森等, 2006), 本文认为错那洞穹窡核部 正下方的低阻高导异常体 $\mathrm{C} 1$ 主要为地壳部分熔融. 但 为了达到约 $2.0 \Omega \cdot \mathrm{m}$ 的平均电阻率值, 纯地壳熔融可能 无法完全满足, 还需加入更高电导率的含盐流体(Comeau等, 2015; Hill等, 2015), 即高导体 C1很可能是上 部含盐流体和下部地壳部分熔融的混合. 而环穹窟(上 拆离断层外侧)分布的低阻异常带 $\mathrm{C} 2 \sim \mathrm{C} 4$, 可类比于火 山区域较浅部分布的低阻异常, 很可能主要为出溶于 深部岩浆或岩浆冷却析出的热液以及岩浆-热液蚀变 岩带(Ogawa等, 2014; Hill等, 2015; Comeau等, 2015; Gao等, 2020), 且不排除在底部可能存在少量部分熔融 体. 同时, 高导异常体 $\mathrm{C} 1$ 上覆的高阻体 $\mathrm{R}$ 位置大致与错 那洞穹窡地表出露的淡色花岗岩范围相一致(图5和6), 分析认为高阻体 $\mathrm{R}$ 应该代表了片麻岩和冷却结晶的花 岗岩(Comeau等, 2015; Hill等, 2015; Gao等, 2020).

当地下流体形成良好的联通网络且使电导率显著 增大时，可以对深部流体含量进行定量估算(Unsworth 等, 2005; Hill等, 2015; Xue等, 2019，2021；Gao等， 
2020; Sun等, 2020; Yu等, 2020), 我们采用Archie公式 对深部流体含量进行定量估算, Archie公式表达式为 (Unsworth等, 2005; Cai等, 2017; Xue等, 2019, 2021)

$\sigma_{\mathrm{eff}}=C \varphi^{n} \sigma_{m}$,

其中, $\varphi$ 为估算的流体含量, $C$ 和 $n$ 为经验系数, 一般取 值 $C=1.47$ 和 $n=1.3$ (Ten Grotenhuis等, 2005), $\sigma_{\text {eff }}$ 代表已 知的有效平均电导率, 即错那洞穹窿核部高电导 $\mathrm{C} 1$ 平 均电阻率约 $2.0 \Omega \cdot \mathrm{m}$ 和环穹䆝高电导 $(\mathrm{C} 2 \sim \mathrm{C} 4)$ 平均电阻 率约 $1.0 \Omega \cdot \mathrm{m}, \sigma_{m}$ 则为纯流体 (部分熔融和含盐流体) 的 电导率, 一般取值 $3 \sim 10 \mathrm{~S} \mathrm{~m}^{-1}$ 或电阻率 $0.1 \sim 0.3 \Omega \cdot \mathrm{m}$ (Unsworth等, 2005; Xue等, 2019, 2021). 图8为纯流体 电导率 $\sigma_{m}$ 为 $3 \sim 10 \mathrm{~S} \mathrm{~m}^{-1}$ 范围时, 平均电阻率 $\sigma_{\mathrm{eff}}$ 随流体 含量的变化, 由图可见, 纯流体电导率 $\sigma_{m}$ 的大小对流 体含量的估算影响较大. 由于含盐流体具有比岩浆更 低的电阻率(Comeau等, 2015; Hill等, 2015), 岩浆中水 含量的多少较大地影响了岩浆电阻率的大小 $(\mathrm{Ni}$ 等, 2011; Gao等, 2020). 目前, 研究认为火山岩浆中水含量 为约 $2 \sim 4 \mathrm{wt} \%$, 相应计算的岩浆电导率为约 $3 \sim 6 \mathrm{~S} \mathrm{~m}^{-1}$ (Vogel-Fulcher-Tammann公式, Gao等(2020)及其引用 文献), 考虑到错那洞穹㶻深部高导异常与火山区域大 地电磁结果的相似性(Hill等, 2009, 2015; Comeau等, 2015; Gao等, 2020), 如果采用纯岩浆和含盐流体电导 率 $\sigma_{m}$ 分别为3 6和5 10S m ${ }^{-1}$, 则错那洞穹窒核部下方 高导异常 $\mathrm{C} 1$ 所代表的地壳部分熔融含量为 11.0 17.3\%, 环穹窡高导异常 $\mathrm{C} 2 \sim \mathrm{C} 4$ 代表的含盐流体 含量为 $12.6 \sim 21.6 \%$.

值得注意的是, 相较于前期在藏南多个地区观测 到的约 $20000 \mathrm{~S}$ 电导和 $0.05 \sim 0.33 \mathrm{~S} \mathrm{~m}^{-1}$ 平均电导率(Unsworth等, 2004, 2005; Dong等, 2016), 错那洞穹窒区域 的大地电磁结果表现为明显较高的电导 (最高电导可 达约 $80000 \mathrm{~S}$, 图7)和平均电导率 $\left(0.5 \sim 1.0 \mathrm{~S} \mathrm{~m}^{-1}\right)$ 以及相 应的较高流体含量. Chen等(2018)通过实验, 研究认为 藏南淡色花岗岩体下方会不断聚集大量的部分熔融 体, 并在深部约 10 13 km产生非常高的电导率值 $\left(>1.0 \mathrm{~S} \mathrm{~m}^{-1}\right)$, 部分熔融含量可达 $(20 \pm 10) \%$, 这些实验结 果与本文高导异常 $\mathrm{C} 1$ 赋存深度(约5 20km, 图6a)和估 算的部分熔融含量(11.0 17.3\%, 图8)大致相符合. 同 时, N-S向裂谷区域的大地电磁数据和动力学模拟结 果均显示裂谷下方可能存在较大范围的中下地壳部分 熔融(Xie C L等, 2017; Pang等, 2018; Liang等, 2018;
Xue等, 2021). 所以本文分析认为错那洞穹窡区域的显 著高导异常应该与穹㶻构造特征及其紧邻的N-S向错 那-沃卡裂谷密切相关.

\section{2 岩浆底辟与东西向伸展作用}

早期研究提出了变质核杂岩模式、岩浆底辟模 式、逆冲断坡模式和中下地壳流模式等多种北喜马拉 雅穹窄构造的形成模式(Le Fort等, 1987; Harrison等, 1997; Beaumont等, 2001, 2004; 李德威等, 2003; Yin, 2006; 张进江, 2007), 而越来越多的研究认为北喜马拉 雅穹窡形成过程中经历了岩浆底辟作用(Le Fort等, 1987; 李德威等, 2003; Lee等, 2006; 张进江, 2007; Guo等, 2008; Zhang等, 2012). 本文的大地电磁结果(图 5 7)显示, 穹窡核部正下方存在显著高导异常 $\mathrm{C} 1$, 呈穹 形构造, 如第 5.1 节所述, 分析认为其主要为地壳部分 熔融结果, 熔融比例达到11.0 17.3\%(图8), 代表了近垂 直上涌的岩浆, 结合错那洞穹窐核部出露的多期次淡 色花岗岩和构造变形(林涁等, 2016; 李光明等, 2017; 高利娥等, 2017; 张志等, 2017; Fu等, 2017, 2018; 夏祥 标等, 2019), 我们支持错那洞穹㶻深部存在岩浆底辟 作用.

关于穹窒深部的岩浆来源, 早期研究认为触发北 喜马拉雅地壳部分熔融的成因主要有三种: 富水熔融 (Le Fort等, 1987)、剪切生热熔融(Harrison等, 1997) 和构造减压熔融(Harris和Massey, 1994). 目前, 越来越 多的研究倾向于在伸展减薄背景下, 构造减压导致中 下地壳变泥质岩中白云母发生了脱水反应, 进而诱发 地壳深熔作用形成了淡色花岗岩(Harris和Massey, 1994; Hou等, 2012; 吴福元等, 2015; 王晓先等, 2016; 高利娥等, 2017). 自中新世以来, 北喜马拉雅经历了早 期近南北向伸展作用和后期近东西向伸展作用 (Burchfiel和Royden, 1985; Armijo等, 1986; Yin, 2006; 许志琴等, 2006; 侯增谦等, 2006; 张进江, 2007; Zhang 和Guo, 2007; Hou等, 2012; Zhang等, 2012; Xue等, 2021), 根据穹㶻的构造变形和运动学特征等, 错那洞 穹窟经历了早期(第二期)南北向伸展和主期(第三期) 东西向伸展活动( $\mathrm{Fu}$ 等, 2017, 2018; 夏祥标等, 2019), 其中, 早期穹窡的南北向伸展变形和核部剥露的中新 世(23 14Ma)淡色花岗岩与其南侧的STDS活动密切相 关(Hou等, 2012; 吴福元等, 2015; 王晓先等, 2016; 林涁 等, 2016; 高利娥等, 2017; Wu等, 2020), 而后期穹窂近 


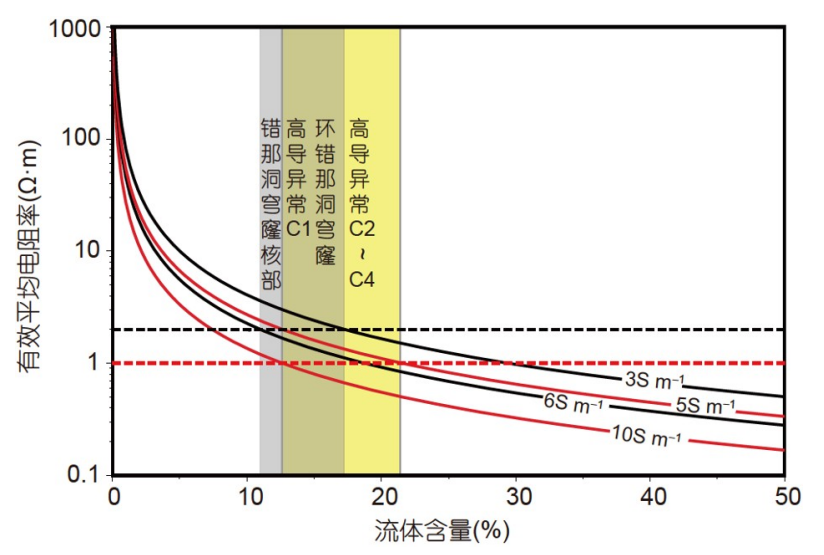

图 8 错那洞穹隆区域高导异常C1 C4流体含量

根据Archie公式估算. 其中对于错那洞穹碾核部的高导异常 $\mathrm{C} 1$, 采 用纯岩浆电导率 $\sigma_{m}=3 \sim 6 \mathrm{~S} \mathrm{~m}^{-1}$, 估算的相应流体含量为 $11.0 \sim 17.3 \%$, 对于环穹窄分布的高导异常 $\mathrm{C} 2 \sim \mathrm{C} 4$, 采用纯含盐流体电导率 $\sigma_{m}=5 \sim 10 \mathrm{~S} \mathrm{~m}^{-1}$, 估算的相应流体含量为 $12.6 \sim 21.6 \%$

东西向构造变形(主期)则与紧邻的近南北向错那-沃卡 裂谷紧密联系(Fu等, 2017, 2018).

青藏高原晚新生代以来的近东西向伸展作用形成 了藏南一系列近南北向的裂谷(Armijo等，1986; Tapponnier等, 2001; Yin, 2006; 许志琴等, 2006; 侯增谦 等, 2006; Zhang和Guo, 2007; 张进江, 2007; Zhang等, 2012; Xue等, 2021), 与错那洞穹窡紧邻的错那-沃卡裂 谷位于藏南裂谷系最东端, 初始裂陷时代早于 5 10Ma，但晚于约 $15 \mathrm{Ma}$ (吴中海等，2007; 哈广浩等, 2018). 横跨雅鲁藏布江缝合带的大量地球物理观测显 示, 南北向裂谷下方普遍分布高导低速层, 被解释为中 下地壳部分熔融层(Unsworth等, 2004, 2005; Nábělek 等, 2009; 金胜等, 2010; Xie C L等, 2017; Pang等, 2018; Liang等, 2018; Xue等, 2021). 错那-沃卡裂谷附近的南 北向大地电磁测线也显示，沿裂谷区域下方存在低阻 异常层(Spratt等, 2005; Xie C L等, 2017). 同时, 错那 洞穹穉核部下方近垂直发育的高导异常 $\mathrm{C} 1$ 及其与围 岩之间的显著电阻率差异，说明高导异常 $\mathrm{C} 1$ 的空间位 置应该代表了深部岩浆运移的前缘通道. 而深部岩浆 上涌通道的建立与深部构造或岩层的变化密切相关, 其中岩层边界或薄弱带是岩浆上涌的优选路径，而且 不同时期的深部岩浆很可能会沿着同一个通道上涌至 地表，而不是建立多个不同的岩浆通道(Hill等，2015). 因此，我们推断错那洞穹窟核部不同时期出露的淡色 花岗岩可能是不同时期的深部岩浆沿同一个通道上涌
的结果. 结合错那洞穹窡的构造特征和出露的多期次 淡色花岗岩以及深部甚低的电阻率异常, 本文研究认 为错那洞穹窡下方高导异常 $\mathrm{C} 1$ (图5 7)所代表的地壳 部分熔融与东西向伸展作用密切相关, 即在东西向伸 展构造背景下, 南北向裂谷区域下方中下地壳发生了 部分熔融, 深部岩浆长期不断地聚集于错那洞穹窒下 方(Chen等, 2018), 并优先沿早期南北向伸展作用下地 壳部分熔融上涌的通道向上运移(Hill等, 2015), 但在 上地壳遭到了早期结晶花岗岩的阻挡，导致岩浆阻塞 于地下，进而发育了岩浆底辟作用，形成了错那洞片 麻岩穹隆构造. 需要注意的是, 北喜马拉雅穹窐构造 很可能是多种构造活动共同作用结果(张进江, 2007), 伸展作用背景下的岩浆底辟作用, 可能只是错那洞穹 緷形成过程中多种成因之一。

\section{3 穹窿构造与多金属成矿作用}

通过对青藏高原碰撞造山和成矿作用的研究, 侯 增谦等(2006)提出了三阶段陆陆碰撞造山成矿作用, 即主碰撞陆陆汇聚成矿作用(约65 41Ma)、晚碰撞构 造转换成矿作用(约40 26Ma) 和后碰撞地壳伸展成矿 作用(约25 0Ma), 三者分别经历了不同的深部过程, 并 驱动了岩浆-热液或热液成矿系统的发育(Hou和Cook, 2009; 侯增谦, 2010). 其中后碰撞期成矿作用强烈而复 杂，是多金属成矿的高峰期(侯增谦等, 2006; 侯增谦, 2010), 该阶段发育的平行碰撞带的构造拆离系统和片 麻岩穹窡构造以及垂直碰撞带的正断层系统和裂谷裂 陷带对成矿至关重要(侯增谦等, 2006; 侯增谦, 2010). 考虑到错那洞穹窟伸展构造特征且同时受到近N-S向 伸展和近E-W向伸展构造影响, 以及穹䆗内高分异淡 色花岗岩成岩成矿年龄 (21 12Ma)(李光明等, 2017; Fu等, 2017, 2018; 梁维, 2019; 梁维等, 2020), 普遍认 为错那洞穹窒的多金属成矿发育于后碰撞地壳伸展环 境, 而成矿物质来源和成矿热动力驱动与STDS和错那 洞穹㶻形成过程中的强烈花岗质岩浆-热液作用密切 相关(聂凤军等, 2005; 侯增谦等, 2006; 杨竹森等, 2006; 李洪梁等, 2017; 娄元林等, 2018).

目前，在错那洞穹窒及其周缘发现了多个(稀有) 多金属矿床(侯增谦等, 2006; 杨竹森等, 2006; 李光明 等, 2017; Xie Y L等, 2017; 张志等, 2017; 梁维, 2019; 梁维等, 2020), 成矿规模巨大. 铍 $(\mathrm{Be}) 、$ 铷 $(\mathrm{Rb}) 、$ 锂 $(\mathrm{Li})$ 等稀有多金属矿床主要分布于错那洞穹㶻的核部和幔 
部, 其中以矽卡岩型矿床分布最为广泛, 矽卡岩矿体主 要分布在环穹㶻分布的大理岩带内(图1b)(李光明等, 2017; 张林奎等, 2018; 夏祥标等, 2019; 梁维等, 2020). 同时，错那洞穹窡周缘发育了大型铅锌、金锑等多金 属矿床(图1b)(聂凤军等, 2005; 侯增谦等, 2006; 杨竹 森等, 2006; Xie Y L等, 2017; 梁维, 2019), 如热液脉型 吉松铅锌矿、热液叠加改造型扎西康铅锌多金属矿和 扎西康晚期锑矿化, 大多数矿床成矿深度 $\leq 3.8 \mathrm{~km}$ (娄元 林等, 2018)和5.8 7.9km(李洪梁等, 2017), 总体显示出 成矿地质环境和成矿流体具浅成性。这些(稀有)多金 属矿床的形成与碰撞造山过程中的构造-岩浆和流体 作用关系密切(侯增谦等, 2006; 杨竹森等, 2006; Xie Y L等, 2017; 娄元林等, 2018; 梁维, 2019; 梁维等, 2020), 涉及的流体有岩浆、岩浆-热液、建造水和大气降水 (聂凤军等, 2005; 侯增谦等, 2006; 李洪梁等, 2017), 而 错那洞穹窡周缘形成的环状展布的糜棱片岩、糜棱岩 和碎屑岩带以及错那-沃卡裂谷侧向拉张形成的正断 层，是控制流体运移通道和浸染状矿化发育的有利部 位(聂凤军等, 2005; 杨竹森等, 2006; 娄元林等, 2018). 由于成矿流体(含岩浆、岩浆-热液等)大都具有很低的 电阻率特征 $(\leq 3 \Omega \cdot \mathrm{m})(\mathrm{GaO}$ 等, 2020$)$, 为了有效展示错那 洞穹窡区域的地下流体立体分布，本文提取了三维电 阻率模型(图 5 和 6 )中 $\leq 3 \Omega \cdot \mathrm{m}$ 等值面(图9). 从图9可以看 出, 以错那洞穹穉为中心, 内部发育来源于深部 $(>15 \mathrm{~km})$ 的高导地壳部分熔融，外部则环穹窡(上拆离 断层外侧)浅部(约2 $8 \mathrm{~km}$ )分布含盐流体等低阻高导异
常, 形成了围绕错那洞穹窒的成矿流体系统, 支持穹窡 构造为岩浆-热液产生、运移、储存等提供了有利空 间(聂凤军等, 2005; 杨竹森等, 2006; 侯增谦等, 2006; 李光明等, 2017). 同时, 比较(稀有)多金属矿床位置和 高导异常分布(图7和8), 可以发现多金属矿床大多位 于高、低导交接部位，可能说明矿床多形成于岩浆和 围岩接触带或热液蚀变带等流体-固态两相转换区域, 但由于本文的大地电磁测点相对比较稀疏，无法准确 可靠的约束高导异常的确切边界.

因此，本文认为错那洞穹窡区域的(稀有)多金属 成矿作用与穹窡构造密切相关, 南北向伸展作用和东 西向伸展作用下的多期次花岗质岩浆作用，提供了丰 富的成矿流体和成矿热动力驱动(聂凤军等, 2005; 侯 增谦等, 2006; 杨竹森等, 2006; 李洪梁等, 2017; 娄元林 等, 2018), 而穹隆构造堑垒式结构和南北向裂谷张性 断裂为含矿热液的迁移、富集成矿提供了有利的空 间, 从而形成了以错那洞穹隆为核心, 从内往外发育了 铍 $(\mathrm{Be})$ 等稀有多金属至铅 $(\mathrm{Pb})$ 、锌 $(\mathrm{Zn})$ 、金 $(\mathrm{Au})$ 、锑 $(\mathrm{Sb})$ 等多金属、从高温至低温的分带成矿作用(聂风 军等, 2005; 杨竹森等, 2006; 侯增谦等, 2006; 李光明 等, 2017; 张林奎等, 2018; 夏祥标等, 2019; 梁维, 2019; 梁维等, 2020).

\section{6 结论}

为了研究北喜马拉雅片麻岩穹窡构造的深部形成

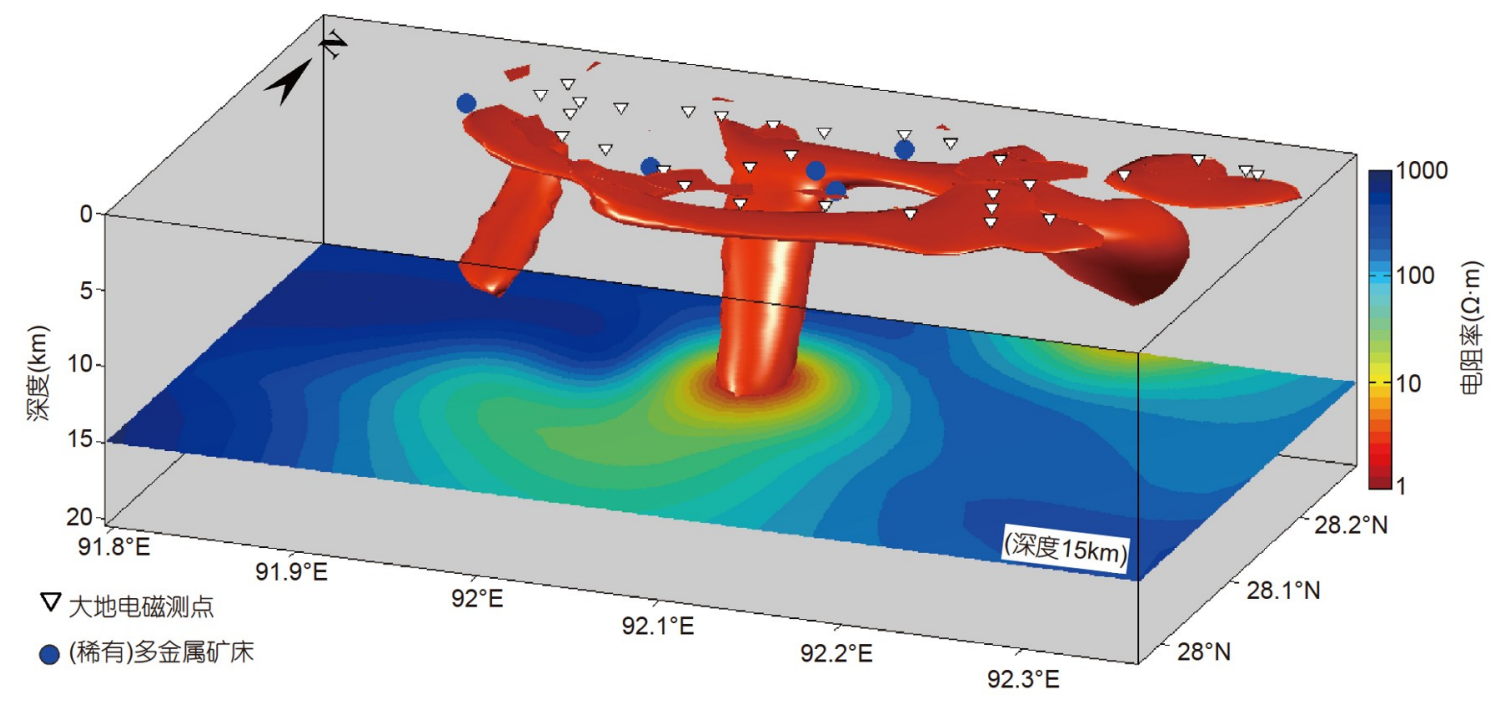

图 9 三维反演电阻率模型中 $\leq 3 \Omega \cdot \mathrm{m}$ 等值面和深度 $15 \mathrm{~km}$ 水平切片 
机制和多金属成矿作用，本文在错那洞穹穉构造区域 开展了大地电磁探测研究. 大地电磁测深曲线和相位 张量显示错那洞穹窡具有比较复杂的三维电性结构和 低阻异常. 通过三维大地电磁反演和灵敏度测试获得 了可靠的错那洞穹窡区域深部电性结构. 三维大地电 磁反演结果显示, 错那洞穹窡核部高阻结构下方存在 显著的穹形低阻异常, 且环穹窒周缘分布明显的低阻 异常带, 两个低阻异常区域沿深度范围1 20km计算的 纵向电导分别平均高达约 10000 和约 20000 S. 其中, 穹 窡核部的高导异常与火山区域深部电性结构非常相 似，分析其代表了地壳部分熔融，估算的熔体含量为 $11.0 \sim 17.3 \%$, 而环穹窿高导异常带应该主要为含盐流 体所致，估算的流体含量为 12.6 21.6\%. 错那洞穹窡 区域的这些显著高导异常可能与穹窟构造特征密切 相关.

综合已有的地质-地球化学研究资料和地球物理 观测结果, 本文大地电磁结果支持错那洞穹隆深部存 在岩浆底辟作用, 且研究认为穹㶻深部的岩浆可能来 源于东西向伸展作用下深部地壳部分熔融，即在青藏 高原后碰撞期东西向伸展作用背景下，错那-沃卡裂谷 区域深部地壳部分熔融长期不断聚集于穹窟下方，但 在上地壳遭到早期结晶花岗岩的阻塞，从而岩浆底辟 形成了错那洞穹窡构造. 同时, 本文大地电磁结果显 示多金属矿床可能多形成于高、低导转换区域，支持 穹窿构造的发育为(稀有)多金属成矿作用提供了丰富 的成矿物质来源、热驱动和含矿流体运移空间，促进 形成了围绕错那洞穹窡的多金属成矿系统.

致谢本文的野外数据由中国地质大学(北京)研究生洪 昊平、吴佳伟和刘哲涵等协助采集。衰心感谢责任编委 和两位若名审稿人的建设性意见.

\section{参考文献}

陈小斌, 叶涛, 蔡军涛, 王立风. 2019. 大地电磁资料精细处理和二维 反演解释技术研究(七) 一云南盈江-龙陵地震区深部电性结构 及孕震环境. 地球物理学报, 62: 1377-1393

董否, 李光明, 王炎, 向安平, 曹华文, 黄波. 2020. 藏南雅拉香波穹稀 角闪片岩的年代学、地球化学及地质意义. 矿物学报, 40: 556567

高利娥, 高家昊, 赵令浩, 侯可军, 唐索寒. 2017. 藏南拿日雍错片麻 岩穹㶻中新世淡色花岗岩的形成过程：变泥质岩部分熔融与分
离结晶作用. 岩石学报, 33: 2395-2411

哈广浩, 吴中海, 何林. 2018. 藏南邛多江地堑的晚新生代沉积地层 及对南北向裂谷形成时代的初步限定. 地质学报, 92: 2051-2067 侯增谦. 2010. 大陆碰撞成矿论. 地质学报, 84: 30-58

侯增谦, 曲晓明, 杨竹森, 孟祥金, 李振清, 杨志明, 郑绵平, 郑有业, 聂风军, 高永丰, 江思宏, 李光明. 2006. 青藏高原碰撞造山带: III. 后碰撞伸展成矿作用. 矿床地质, 25: 629-651

胡祥云, 林武乐, 杨文采, 杨博. 2020. 克拉通岩石圈电性结构研究进 展. 中国科学: 地球科学, 50: 1533-1552

焦彦杰, 黄旭日, 李光明, 梁生贤, 郭镜. 2019. 藏南扎西康矿集区深 部结构与成矿: 来自地球物理的证据. 地球科学, 44: 2117-2128 金胜, 魏文博, 汪硕, 叶高峰, 邓明, 谭捍东. 2010. 青藏高原地壳高导 层的成因及动力学意义探讨 一大地电磁探测提供的证据. 地 球物理学报, 53: 2376-2385

李德威, 刘德民, 廖群安, 张雄华, 袁晏明. 2003. 藏南萨迦拉轨岗日 变质核杂岩的厘定及其成因. 地质通报, 22: 303-307

李光明, 张林奎, 焦彦杰, 夏祥标, 董随亮, 付建刚, 梁维, 张志, 吴建 阳, 董否, 黄勇. 2017. 西藏喜马拉雅成矿带错那洞超大型铍锡铇 多金属矿床的发现及意义. 矿床地质, 36: 1003-1008

李洪梁, 李光明, 李应棚, 董随亮, 卿成实, 付建刚, 刘洪, 黄瀚霄. 2017. 藏南扎西康矿集区姐纳各普金矿床地质与流体包裹体特 征. 矿物学报, 37: 684-695

李世文, 翁爱华, 李建平, 单玄龙, 韩江涛, 唐裕, 张艳辉, 王雪秋. 2020. 三维电性结构揭示的中国东北地区新生代火山深部起源. 中国科学: 地球科学, 50: 538-552

梁维. 2019. 特提斯喜马拉雅金锑铅锌多金属成矿带成矿流体特征: 来自H-O同位素的约束. 地球科学, 44: 2308-2318

梁维, 李光明, 张林奎, 付建刚, 黄勇, 张志. 2020. 藏南错那洞铍稀有 多金属成矿时代: 来自热液白云母Ar-Ar年龄的约束. 沉积与特 提斯地质, 40: 76-81

林森, 唐菊兴, 郑文宝, 冷秋锋, 林坴, 王艺云, 孟展, 唐悸, 丁帅, 徐云 峰，袁梅. 2016. 西藏错那洞淡色花岗岩地球化学特征、成岩时 代及岩石成因. 岩石矿物学杂志, 35: 391-406

娄元林, 陈武, 袁永盛, 杨桃. 2018. 西藏隆子县恰嘎锑矿床流体包裹 体及H、O、S同位素组成特征. 矿床地质, 37: 1124-1140

聂风军, 胡朋, 江思宏, 李振清, 刘妍, 周永章. 2005. 藏南地区金和锑 矿床(点)类型及其时空分布特征. 地质学报, 79: 373-284

王汝成, 吴福元, 谢否, 刘小驰, 王佳敏, 杨雷, 赖文, 刘晨. 2017. 藏南 喜马拉雅淡色花岗岩稀有金属成矿作用初步研究. 中国科学: 地 球科学, 47: 871-880

王晓先, 张进江, 间淑玉, 刘江. 2016. 藏南错那淡色花岗岩LA-MCICP-MS锆石U-Pb年龄、岩石地球化学及其地质意义. 地质通报, 35: 91-103

王绪本, 张刚, 周军, 李德伟, 罗威, 胡元邦, 蔡学林, 郭紫明. 2018. 龙 门山构造带壳幔电性结构特征及其与汶川、芦山强震关系. 地 球物理学报, 61: 1984-1995 
吴福元, 刘志超, 刘小驰, 纪伟强. 2015. 喜马拉雅淡色花岗岩. 岩石 学报, 31: 1-36

吴中海, 张永双, 胡道功, 赵希涛, 叶培盛. 2007. 西藏错那-沃卡裂谷 带中段邛多江地堑晚新生代正断层作用. 地质力学学报, 13: 297-306

夏祥标, 李光明, 曹华文, 梁维, 付建刚. 2019. 西藏南部错那洞矽卡 岩型铍铇锡多金属矿体成矿母岩成岩时代及其地球化学特征. 地球科学, 44: 2207-2223

徐义贤, 郑建平, 杨晓志, 夏群科. 2019. 岩石圈中部不连续面的成因 及其动力学意义. 科学通报, 64: 2305-2315

许志琴, 杨经绥, 戚学祥, 崔军文, 李海兵, 陈方远. 2006. 印度/亚洲碰 撞-南北向和东西向拆离构造与现代喜马拉雅造山机制再讨论. 地质通报, 25: 1-14

杨竹森, 侯增谦, 高伟, 王海平, 李振清, 孟祥金, 曲晓明. 2006. 藏南 拆离系锑金成矿特征与成因模式. 地质通报, 80: 1377-1390

殷长春, 刘云鹤, 熊涁. 2020. 地球物理三维电磁反演方法研究动态. 中国科学: 地球科学, 50: 432-435

曾令森, 刘静, 高利娥, 谢克家, 文力. 2009. 藏南也拉香波穹隆早渐 新世地壳深熔作用及其地质意义. 科学通报, 54: 373-381

张波, 张进江, 郭否, 王维亮. 2005. 北喜马拉雅穹窡带雅拉香波变质 核杂岩拆离断层系中糜棱岩带构造特征及变形分析. 自然科学 进展, 15: 692-698

张进江. 2007. 北喜马拉雅及藏南伸展构造综述. 地质通报, 26: 639649

张林奎, 张志, 李光明, 董随亮, 夏祥标, 梁维, 付建刚, 曹华文. 2018 . 特提斯喜马拉雅错那洞穹隆的岩石组合、构造特征与成因. 地 球科学, 43: 2664-2683

张志, 张林奎, 李光明, 梁维, 夏祥标, 付建刚, 董随亮, 马国桃. 2017. 北喜马拉雅错那洞穹隆: 片麻岩穹隆新成员与穹隆控矿新命题. 地球学报, 38: 754-766

Armijo R, Tapponnier P, Mercier J L, Han T L. 1986. Quaternary extension in southern Tibet: Field observations and tectonic implications. J Geophys Res, 91: 13803-13872

Bai D, Unsworth M J, Meju M A, Ma X B, Teng J W, Kong X R, Sun Y, Sun J, Wang L F, Jiang C S, Zhao C P, Xiao P F, Liu M. 2010. Crustal deformation of the eastern Tibetan Plateau revealed by magnetotelluric imaging. Nat Geosci, 3: 358-362

Bao X W, Sun X X, Xu M J, Eaton D W, Song X D, Wang L S, Ding Z F, Mi N, Li H, Yu D Y, Huang Z C, Wang P. 2015. Two crustal lowvelocity channels beneath SE Tibet revealed by joint inversion of Rayleigh wave dispersion and receiver functions. Earth Planet Sci Lett, 415: 16-24

Beaumont C, Jamieson R A, Nguyen M H, Lee B. 2001. Himalayan tectonics explained by extrusion of a low-viscosity crustal channel coupled to focused surface denudation. Nature, 414: 738-742

Beaumont C, Jamieson R A, Nguyen M H, Medvedev S. 2004. Crustal channel flows: 1. Numerical models with applications to the tectonics of the Himalayan-Tibetan orogen. J Geophys Res-Solid Earth, 109: B06406

Bibby H M, Caldwell T G, Brown C. 2005. Determinable and nondeterminable parameters of galvanic distortion in magnetotellurics. Geophys J Int, 163: 915-930

Booker J R. 2014. The magnetotelluric phase tensor: A critical review. Surv Geophys, 35: 7-40

Burchfiel B C, Royden L H. 1985. North-south extension within the convergent Himalayan region. Geology, 13: 679-682

Burg J P, Brunel M, Gapais D, Chen G M, Liu G H. 1984. Deformation of leucogranites of the crystalline Main Central Sheet in southern Tibet (China). J Struct Geol, 6: 535-542

Cai J C, Wei W, Hu X Y, Wood D A. 2017. Electrical conductivity models in saturated porous media: A review. Earth-Sci Rev, 171: 419-433

Caldwell T G, Bibby H M, Brown C. 2004. The magnetotelluric phase tensor. Geophys J Int, 158: 457-469

Chen J Y, Gaillard F, Villaros A, Yang X S, Laumonier M, Jolivet L, Unsworth M, Hashim L, Scaillet B, Richard G. 2018. Melting conditions in the modern Tibetan crust since the Miocene. Nat Commun, 9: 3515

Clark M K, Royden L H. 2000. Topographic ooze: Building the eastern margin of Tibet by lower crustal flow. Geology, 28: 703-706

Comeau M J, Unsworth M J, Ticona F, Sunagua M. 2015. Magnetotelluric images of magma distribution beneath Volcán Uturuncu, Bolivia: Implications for magma dynamics. Geology, 43: 243-246

Dong H, Wei W B, Jin S, Ye G F, Zhang L T, Jing J E, Yin Y T, Xie C L, Jones A G. 2016. Extensional extrusion: Insights into southeastward expansion of Tibetan Plateau from Magnetotelluric array data. Earth Planet Sci Lett, 454: 78-85

Dong H, Wei W B, Jin S, Ye G F, Jones A G, Zhang L T, Jing J E, Xie C L, Yin Y T. 2020. Shaping the surface deformation of central and south Tibetan Plateau: Insights from magnetotelluric array data. J Geophys Res-Solid Earth, 125: e19206

Dong X, Li W H, Lu Z W, Huang X F, Gao R. 2020. Seismic reflection imaging of crustal deformation within the eastern Yarlung-Zangbo suture zone. Tectonophysics, 780: 228395

Egbert G D. 1997. Robust multiple-station magnetotelluric data processing. Geophys J Int, 130: 475-496

Egbert G D, Kelbert A. 2012. Computational recipes for electromagnetic inverse problems. Geophys J Int, 189: 251-267

Fu J G, Li G M, Wang G H, Huang Y, Zhang L K, Dong S L, Liang W. 2017. First field identification of the Cuonadong dome in southern Tibet: Implications for EW extension of the North Himalayan gneiss 
dome. Int J Earth Sci-Geol Rundsch, 106: 1581-1596

Fu J G, Li G M, Wang G H, Zhang L K, Liang W, Zhang Z, Zhang X Q,

Huang Y. 2018. Synchronous granite intrusion and E-W extension in the Cuonadong dome, southern Tibet, China: Evidence from field observations and thermochronologic results. Int J Earth Sci-Geol Rundsch, 107: 2023-2041

Gao R, Lu Z W, Klemperer S L, Wang H Y, Dong S W, Li W H, Li H Q. 2016. Crustal-scale duplexing beneath the Yarlung Zangbo suture in the western Himalaya. Nat Geosci, 9: 555-560

Gao J, Zhang H J, Zhang S Q, Xin H L, Li Z W, Tian W, Bao F, Cheng Z P, Jia X F, Fu L. 2020. Magma recharging beneath the Weishan volcano of the intraplate Wudalianchi volcanic field, northeast China, implied from 3-D magnetotelluric imaging. Geology, 48: 913-918

Guo L, Zhang J, Zhang B. 2008. Structures, kinematics, thermochronology and tectonic evolution of the Ramba gneiss dome in the northern Himalaya. Prog Nat Sci, 18: 851-860

Harris N, Massey J. 1994. Decompression and anatexis of Himalayan metapelites. Tectonics, 13: 1537-1546

Harrison T M, Lovera O M, Grove M. 1997. New insights into the origin of two contrasting Himalayan granite belts. Geology, 25: 899-902

Hashim L, Gaillard F, Champallier R, Le Breton N, Arbaret L, Scaillet B. 2013. Experimental assessment of the relationships between electrical resistivity, crustal melting and strain localization beneath the Himalayan-Tibetan Belt. Earth Planet Sci Lett, 373: 20-30

Heise W, Pous J. 2003. Anomalous phases exceeding $90^{\circ}$ in magnetotellurics: Anisotropic model studies and a field example. Geophys J Int, 155: 308-318

Hill G J, Caldwell T G, Heise W, Chertkoff D G, Bibby H M, Burgess M K, Cull J P, Cas R A F. 2009. Distribution of melt beneath Mount St Helens and Mount Adams inferred from magnetotelluric data. Nat Geosci, 2: 785-789

Hill G J, Bibby H M, Ogawa Y, Wallin E L, Bennie S L, Caldwell T G, Keys H, Bertrand E A, Heise W. 2015. Structure of the Tongariro Volcanic system: Insights from magnetotelluric imaging. Earth Planet Sci Lett, 432: 115-125

Hou Z Q, Cook N J. 2009. Metallogenesis of the Tibetan collisional orogen: A review and introduction to the special issue. Ore Geol Rev, 36: 2-24

Hou Z Q, Zheng Y C, Zeng L S, Gao L E, Huang K X, Li W, Li Q Y, Fu Q, Liang W, Sun Q Z. 2012. Eocene-Oligocene granitoids in southern Tibet: Constraints on crustal anatexis and tectonic evolution of the Himalayan orogen. Earth Planet Sci Lett, 349350: $38-52$

Le Fort P, Cuney M, Deniel C, France-Lanord C, Sheppard S M F,
Upreti B N, Vidal P. 1987. Crustal generation of the Himalayan leucogranites. Tectonophysics, 134: 39-57

Lee J, Hacker B R, Dinklage W S, Wang Y, Gans P, Calvert A, Wan J L, Chen W J, Blythe A E, McClelland W. 2000. Evolution of the Kangmar Dome, southern Tibet: Structural, petrologic, and thermochronologic constraints. Tectonics, 19: 872-895

Lee J, McClelland W, Wang Y, Blythe A, McWilliams M. 2006. Oligocene-Miocene middle crustal flow in southern Tibet: Geochronology of Mabja Dome. Geol Soc London Spec Publ, 268: 445469

Li H Q, Gao R, Li W H, Carbonell R, Yelisetti S, Huang X F, Shi Z X, Lu Z W. 2021. The Mabja dome structure in southern Tibet revealed by deep seismic reflection data and its tectonic implications. J Geophys Res-Solid Earth, 126: e20265

Liang H D, Jin S, Wei W B, Gao R, Ye G F, Zhang L T, Yin Y T, Lu Z W. 2018. Lithospheric electrical structure of the middle Lhasa terrane in the south Tibetan Plateau. Tectonophysics, 731-732: 95103

Meqbel N M, Egbert G D, Wannamaker P E, Kelbert A, Schultz A. 2014. Deep electrical resistivity structure of the northwestern U.S. derived from 3-D inversion of USArray magnetotelluric data. Earth Planet Sci Lett, 402: 290-304

Meqbel N M, Weckmann U, Muñoz G, Ritter O. 2016. Crustal metamorphic fluid flux beneath the Dead Sea Basin: Constraints from 2-D and 3-D magnetotelluric modelling. Geophys J Int, 207: $1609-1629$

Nábělek J, Hetényi G, Vergne J, Sapkota S, Kafle B, Jiang M, Su H P, Chen J, Huang B S, the Hi-Climb Team. 2009. Underplating in the Himalaya-Tibet collision zone revealed by the Hi-CLIMB experiment. Science, 325: 1371-1374

Ni H W, Keppler H, Behrens H. 2011. Electrical conductivity of hydrous basaltic melts: Implications for partial melting in the upper mantle. Contrib Mineral Petrol, 162: 637-650

Ogawa Y, Ichiki M, Kanda W, Mishina M, Asamori K. 2014. Threedimensional magnetotelluric imaging of crustal fluids and seismicity around Naruko volcano, NE Japan. Earth Planet Sp, 66: 158

Pang Y J, Zhang H, Gerya T V, Liao J, Cheng H H, Shi Y L. 2018. The mechanism and dynamics of N-S rifting in southern Tibet: Insight from 3-D thermomechanical modeling. J Geophys Res-Solid Earth, 123: 859-877

Spratt J E, Jones A G, Nelson K D, Unsworth M J. 2005. Crustal structure of the India-Asia collision zone, southern Tibet, from INDEPTH MT investigations. Phys Earth Planet Inter, 150: 227237

Sun X Y, Zhan Y, Unsworth M M, Egbert G, Zhang H P, Chen X B, Zhao G Z, Sun J B, Zhao L Q, Cui T F, Liu Z Y, Han J. 2020. 3-D 
magnetotelluric imaging of the easternmost Kunlun Fault: Insights into strain partitioning and the seismotectonics of the Jiuzhaigou $M_{\mathrm{s}} 7.0$ earthquake. J Geophys Res-Solid Earth, 125: e19731

Tapponnier P, Xu Z, Roger F, Meyer B, Arnaud N, Wittlinger G, Yang J. 2001. Oblique stepwise rise and growth of the Tibet Plateau. Science, 294: 1671-1677

Ten Grotenhuis S M, Drury M R, Spiers C J, Peach C J. 2005. Melt distribution in olivine rocks based on electrical conductivity measurements. J Geophys Res, 110: B12201

Unsworth M J, Wei W B, Jones A G, Li S H, Bedrosian P, Booker J, Sheng J, Ming D, Tan H D. 2004. Crustal and upper mantle structure of northern Tibet imaged with magnetotelluric data. J Geophys Res, 109: B02403

Unsworth M J, Jones A G, Wei W B, Marquis G, Gokarn S G, Spratt J E, The INDEPTH-MT Team. 2005. Crustal rheology of the Himalaya and Southern Tibet inferred from magnetotelluric data. Nature, 438: 78-81

Wu F Y, Liu X C, Liu Z C, Wang R C, Xie L, Wang J M, Ji W Q, Yang L, Liu C, Khanal G P, He S X. 2020. Highly fractionated Himalayan leucogranites and associated rare-metal mineralization. Lithos, 352353: 105319

Xiao Q B, Zhang J, Zhao G Z, Wang J J. 2013. Electrical resistivity structures northeast of the Eastern Kunlun Fault in the Northeastern Tibet: Tectonic implications. Tectonophysics, 601: 125-138

Xie C L, Jin S, Wei W B, Ye G F, Zhang L T, Dong H, Yin Y T. 2017. Varying Indian crustal front in the southern Tibetan Plateau as revealed by magnetotelluric data. Earth Planets Space, 69: 147

Xie Y L, Li L M, Wang B G, Li G M, Liu H F, Li Y X, Dong S L, Zhou J J. 2017. Genesis of the Zhaxikang epithermal Pb-Zn-Sb deposit in southern Tibet, China: Evidence for a magmatic link. Ore Geol Rev, 80: 891-909

Xue S, Bai D, Chen Y, Ma X B, Chen L, Li X, Yan Y L. 2019. Contrasting crustal deformation mechanisms in the Longmenshan and West Qinling orogenic belts, NE Tibet, revealed by magnetotelluric data. J Asian Earth Sci, 176: 120-128

Xue S, Chen Y, Liang H D, Li X, Liang X F, Ma X B, Lu Z W, Bai D
H, Yan Y L. 2021. Deep electrical resistivity structure across the Gyaring Co Fault in Central Tibet revealed by magnetotelluric data and its implication. Tectonophysics, 809: 228835

Ye T, Huang Q H, Chen X B, Zhang H Q, Chen Y J, Zhao L, Zhang Y. 2018. Magma chamber and crustal channel flow structures in the Tengchong volcano area from 3-D MT inversion at the intracontinental block boundary southeast of the Tibetan Plateau. J Geophys Res-Solid Earth, 123: 11112-11126

Yin A. 2006. Cenozoic tectonic evolution of the Himalayan orogen as constrained by along-strike variation of structural geometry, exhumation history, and foreland sedimentation. Earth-Sci Rev, 76: $1-131$

Yu N, Unsworth M, Wang X B, Li D W, Wang E C, Li R H, Hu Y B, Cai X L. 2020. New insights into crustal and mantle flow beneath the Red River Fault zone and adjacent areas on the southern margin of the Tibetan Plateau revealed by a 3-D magnetotelluric study. J Geophys Res-Solid Earth, 125: e19396

Zeng L S, Gao L E, Xie K J, Liu-Zeng J. 2011. Mid-Eocene high Sr/Y granites in the Northern Himalayan Gneiss Domes: Melting thickened lower continental crust. Earth Planet Sci Lett, 303: 251266

Zhang H Q, Huang Q H, Zhao G Z, Guo Z, Chen Y S. 2016. Threedimensional conductivity model of crust and uppermost mantle at the northern Trans North China Orogen: Evidence for a mantle source of Datong volcanoes. Earth Planet Sci Lett, 453: 182-192

Zhang J J, Guo L. 2007. Structure and geochronology of the southern Xainza-Dinggye rift and its relationship to the south Tibetan detachment system. J Asian Earth Sci, 29: 722-736

Zhang J J, Santosh M, Wang X X, Guo L, Yang X Y, Zhang B. 2012. Tectonics of the northern Himalaya since the India-Asia collision. Gondwana Res, 21: 939-960

Zhao G Z, Unsworth M J, Zhan Y, Wang L F, Chen X B, Jones A G, Tang J, Xiao Q B, Wang J J, Cai J T, Li T, Wang Y Z, Zhang J H. 2012. Crustal structure and rheology of the Longmenshan and Wenchuan $M_{\mathrm{w}} 7.9$ earthquake epicentral area from magnetotelluric data. Geology, 40: 1139-1142 